\title{
Percepção dos profissionais de enfermagem quanto à assistência prestada às mulheres em processo de abortamento provocado
}

\author{
Perception of nursing professionals regarding the assistance provided to women in the \\ process of induced abortion
}
Percepción de los profesionales de enfermería sobre la asistencia brindada a las mujeres en el proceso de aborto inducido

\begin{abstract}
Carolina Moriyama Silva ${ }^{1 *}$, Carolina Torres de Paula ${ }^{1}$, Leticia Oliveira Moraes ${ }^{1}$, Daniela Cristina Zica Silva'.
\end{abstract}

\section{RESUMO}

Objetivo: Compreender a percepção dos profissionais de enfermagem quanto à assistência prestada às mulheres em processo de abortamento provocado. Métodos: Trata-se de uma pesquisa transversal, com abordagem qualitativa. Foram realizadas entrevistas com profissionais de enfermagem, os quais responderam um questionário disponibilizado pormeio de um link na plataforma Google Forms®. Resultados: Participaram da pesquisa 19 profissionais do sexo feminino, com prevalência de idade entre 25 a 34 anos (42,1\%). Observou-se um maior número de participantes que realizaram alguma especialização profissional (47,4\%). Após a coleta e interpretação das falas, estas foram organizadas em dois temas: "Preparação", do qual surgiram as categorias: falta de preparo, emoção e humanização; "Sentimentos", do qual surgiram as categorias: julgamento, empatia e ética. O preparo técnico e emocional das profissionais é um fator que está diretamente associado à segurança assistencial. Durante a assistência às mulheres, devem ser assegurados: privacidade, resolutividade, atendimento integral, acolhimento, empatia e atendimento humanizado. Conclusão: Os profissionais de enfermagem são de grande relevância na atividade da escuta e do acolhimento, proporcionando um atendimento humanizado e holístico àquela mulher, permitindo que o ambiente fique confortável para que elas possam expressar suas verdadeiras aflições e nortear a cond uta adequada em cada situação.

Palavras-chave: Assistência de enfermagem, Saúde da mulher, Aborto, Enfermagem.

\begin{abstract}
Objective: To understand the perception of nursing professionals regarding the assistance provided to women undergoing an induced abortion process. Methods: This is a cross-sectional study with a qualitative approach. Interviews were conducted with nursing professionals, who answered a questionnaire made available through a link on the Google Forms ${ }^{\circledR}$ platform. Results: Nineteen female professionals participated in the research, with a prevalence aged between 25 and 34 years $(42.1 \%)$. There was a greater number of participants who had some professional specialization (47.4\%). After collecting and interpreting the statements, they were organized into two themes: "Preparation", from which the following categories emerged: lack of preparation, emotion and humanization; "Feelings", from which the following categories emerged: judgment, empathy and ethics. The professionals' technical and emotional preparation is a factor that is directly associated with care security. During assistance to women, the following must be ensured: privacy, resoluteness, comprehensive care, welcoming, empathy and humanized care. Conclusion: Nursing professionals are of great importance in the activity of listening and welcoming, providing a humanized and holistic service to that woman, allowing the environment to be comfortable so that they can express their true afflictions and guide the appropriate conduct in each situation.
\end{abstract}

Key words: Nursing care, Women's health, Abortion, Nurse.

\footnotetext{
${ }^{1}$ Centro Universitário Newton Paiva, Belo Horizonte - MG. *E-mail: moriyamacaro|@gmail.com
} 


\section{RESUMEN}

Objetivo: Comprender la percepción de los profesionales de enfermería sobre la asistencia brindada a las mujeres sometidas a un proceso de aborto inducido. Métodos: Se trata de un estudio transversal con enfoque cualitativo. Se realizaron entrevistas con profesionales de enfermería, quienes respondieron un cuestionario disponible a través de un enlace en la plataforma Google Forms ${ }^{\circledR}$. Resultados: Participaron de la investigación 19 mujeres profesionales, con una prevalencia de entre 25 y 34 años (42,1\%). Hubo un mayor número de participantes que tenían alguna especialización profesional $(47,4 \%)$. Después de recopilar e interpretar las declaraciones, se organizaron en dos temas: "Preparación", de donde surgieron las siguientes categorías: falta de preparación, emoción y humanización; "Sentimientos", de los que surgieron las siguientes categorías: juicio, empatía y ética. La preparación técnica y emocional de los profesionales es un factor directamente asociado a la seguridad asistencial. Durante la atención a las mujeres se debe garantizar: privacidad, resolución, atención integral, acogida, empatía y atención humanizada. Conclusión: Los profesionales de enfermería son de gran importancia en la actividad de escuchar y acoger, brindando un servicio humanizado y holístico a esa mujer, permitiendo que el ambiente sea confortable para que puedan expresar sus verdaderas aflicciones y orientar la conducta adecuada en cada situación.

Palabras clave: Cuidados de enfermería, Salud de la mujer, Aborto, Enfermería.

\section{INTRODUÇÃO}

O aborto é considerado um assunto polêmico, permeado por várias posições morais e conflitos legais. Entender a dimensão associada ao aborto provocado, na busca por soluções, demanda investimento não apenas dos profissionais de saúde, mas também da educação, levando informação às mulheres e, principalmente, no engajamento decisivo do Estado (SANTOS VC, et al., 2013).

A não legalidade do aborto no Brasil não tem impossibilitado sua prática, a qual transcorre em várias circunstâncias e utilizando desde métodos seguros, permitidos pela lei, a métodos clandestinos e com riscos iminentes de morte da mulher. É apontado como problema de saúde pública em todo o mundo e de grande relevância em discussões associadas à saúde da mulher (SOARES FP, et al ., 2018).

No Brasil, o Código Penal proíbea realização de aborto, exceto nos casos de gravidez resultante de abuso sexual ou quando coloca em risco a saúde da mulher (BRASIL, 1940). Além desses dois casos, o Supremo Tribunal Federal decidiu, desde 2012, permitir a interrupção da gestação quando comprovada anencefalia (BRASIL, 2012a). Essas são situações que recebem apoio de categorias da saúde, como salientado no Código de Ética dos Profissionais de Enfermagem publicado pelo Conselho Federal de Enfermagem (COFEN) (2017).

Diante disso, algumas mulheres, que desejam interromper a gravidez nos casos não previstos pela Lei, optam por fazer procedimentos clandestinos e que, muitas vezes, colocam suas vidas em risco devido às complicações potenciais. De acordo com o Ministério da Saúde (MS), estima-se que cerca de um milhão de mulheres realizam o aborto provocado por ano no Brasil. Ainda de acordo com o Órgão, dessas mulheres, cerca de 15 mil apresentam complicações e cinco mil são internadas com gravidade (COFEN, 2018).

A Pesquisa Nacional de Aborto (PNA), realizada no ano de 2016, mostrou que, entre as 2002 mulheres entrevistadas alfabetizadas entre 18 e 39 anos, 251 (13\%) já realizaram ao menos um aborto e que aos 40 anos de idade, quase uma em cada cinco mulheres já provocou aborto (DINIZ D, et al., 2017). Contudo, as estatísticas são imprecisas, pois as análises têm como obstáculos a discriminação e a condenação moral da prática de abortamento no Brasil (SILVEIRA P, 2016).

Dados do COFEN (2018) apontam que o aborto inseguro causou a morte de 203 mulheres no ano de 2016, sendo a segunda maior causa de internação nas Unidades de Emergência Obstétrica no Brasil. O aborto está entre as quatro principais causas de mortalidade materna no país. Os dados referentes à hospitalização no Sistema Único de Saúde (SUS) mostram que a curetagem pós-aborto representa um dos procedimentos obstétricos mais executados, representando 95\% dos casos (SOARES FP, et al., 2018). 
A Política Nacional de Atenção Integral à Saúde da Mulher (PAISM) preconiza, em seus objetivos específicos, a promoção da atenção obstétrica e neonatal de forma especializada e humanizada, englobando a assistência ao abortamento em condições inseguras, para mulheres e adolescentes (BRASIL, 2004).

O aborto praticado em circunstâncias inseguras, além de estar entre as principais causas de morte materna no Brasil, é motivo de discriminação e violência organizacional contra as mulheres nos serviços de saúde. Essa violência pode ser manifestada na demora ao atendimento, na ausência de disposição das equipes em acolher e orientar as mulheres, ocorrendo, em alguns casos, discriminação explícita com palavras pejorativas. Tendo em vista que a maioria das mulheres que passaram por processo abortivo estão entre as usuárias que sofreram algum tipo de negligência referente aos cuidados de promoção da saúde reprodutiva, incluindo acesso ao planejamento familiar, verifica-se que poucas ações são realizadas para que esse processo não ocorra novamente (BRASIL, 2011).

No momento da chegada das mulheres em processo de abortamento provocado, a experiência é física, emocional e social. Elas chegam ao serviço mais sensibilizadas em relação ao processo do abortamento em si e como serão recepcionadas no atendimento, carregando consigo medos e dúvidas. Nesse contexto, os profissionais de enfermagem são capazes de vivenciar diversos tipos de sentimentos (BRASIL, 2011). A falta de humanização nos atendimentos a essas mulheres é uma realidade, causando ainda mais sofrimento do que o procedimento em si proporciona. Os profissionais de enfermagem não devem se esquecer do olhar holístico, de estarem abertos à escuta quanto às queixas da mulher, as quais não são apenas físicas, mas também emocionais e sociais, e não devem colocar suas questões pessoais acima do atendimento (SOARES FP, et al., 2018).

É necessário que o profissional de saúde tenha conhecimento da classificação adequada do abortamento para que a conduta seja definida adequadamente. Os diferentes métodos disponíveis devem estar acessíveis à escolha da mulher, considerando também a decisão clínica dos profissionais. O planejamento reprodutivo pós-abortamento deve fazer parte do processo. As mulheres com complicações de abortamento devem ser orientadas e acompanhadas para que o mesmo problema não volte a acontecer. Nos casos de abortamento provocado, a utilização rápida de contracepção tem se mostrado eficaz para a diminuição de riscos de novos abortamentos (BRASIL, 2011).

Apesar de haver publicações acerca desta temática na literatura, ainda há muito a ser investigado sobre a atuação da equipe de enfermagem. Desta forma, a presente pesquisa teve como objetivo responder à seguinte pergunta: Qual é a percepção dos profissionais de enfermagem quanto à assistência prestada às mulheres em processo de abortamento provocado?

\section{MÉTODOS}

Trata-se de uma pesquisa transversal, com abordagem qualitativa, a qual utiliza os métodos que auxiliam o desenvolvimento da pesquisa de forma coerente. O estudo em questão busca responder a seguinte pergunta norteadora: Qual é a percepção dos profissionais de enfermagem quanto à assistência prestada às mulheres em processo de abortamento provocado?

$\mathrm{Na}$ busca para a realização deste estudo, não foram encontradas pesquisas atuais que apontassem especificamente sobre como ocorre a atuação da equipe de enfermagem em situações de abortamento provocado.

Para a elaboração do estudo, foram aplicadas as seguintes etapas: elaboração da pergunta norteadora; busca/amostragem na literatura e coleta de dados (por três revisores independentes); análise crítica dos estudos incluídos; discussão dos resultados e apresentação da pesquisa.

Foram convidados a participar da pesquisa os profissionais de enfermagem que atuam frente ao atendimento das mulheres em processo de abortamento. Os critérios para a inclusão foram: enfermeiros e técnicos de enfermagem que prestam assistência direta às pacientes que vivenciam o processo de abortamento. Foram excluídos os participantes que não responderam ao questionário completo. 
Para a coleta de dados, utilizou-se um questionário construído pelas autoras. A primeira parte foi composta por variáveis sociodemográficas e relativas à experiência profissional, elaborada em questões fechadas, contendo os seguintes dados: sexo, idade, formação acadêmica (técnica, ensino superior, especialização, mestrado, doutorado), tempo de experiência profissional e tempo de atuação na área obstétrica.

A segunda parte foi composta por questões abertas sobre a percepção dos profissionais de enfermagem em relação ao processo de abortamento provocado, as quais seguem: 1 - Como você se sente ao prestar assistência de enfermagem a uma paciente que provocou o aborto?; 2 - Como você considera o seu preparo técnico e emocional para lidar com mulheres em processo de abortamento provocado?; 3 - Você acha que em seu local de trabalho os profissionais de enfermagem sabem lidar com as situações do abortamento provocado? Explique; 4 - Como você acredita que deve ser a abordagem pelos profissionais de enfermagem frente ao processo de abortamento provocado?

Aos profissionais de enfermagem escolhidos através da busca pelos currículos na plataforma Linkedin ${ }^{\circledR}$ e demais redes sociais, foi enviado um link para acesso ao questionário virtual cadastrado na plataforma online Google Forms ${ }^{\circledR}$, que incluía a apresentação da pesquisa e seus objetivos, além do Termo de Consentimento Livre e Esclarecido (TCLE). A partir dos profissionais selecionados, utilizou-se também a Snowball Sampling ("Bola de Neve"), uma técnica de amostragem que utiliza cadeias de referência, uma espécie de rede (HECKATHORN DD, 1997).

Como proposto por Mendes RM e Miskulin RGS (2017), as respostas obtidas às perguntas qualitativas foram estratificadas de acordo com as unidades de interesse para o estudo e, assim, compuseram um banco de dados, onde tais unidades foram padronizadas e agrupadas conforme a semelhança das ideias centrais apresentadas: 'a percepção da equipe de enfermagem quanto à assistência of erecida à mulher em processo de abortamento provocado' e 'a assistência ideal à mulher em processo de abortamento provocado de acordo com a percepção da equipe de enfermagem'. Os profissionais entrevistados foram identificados por número para garantir o anonimato.

Em seguida, os dados foram analisados a partir do material organizado na etapa anterior. A técnica realizada para a análise qualitativa dos dados utilizou como base o método de Análise Temática de Conteúdo (BARDIN L, 2010). As três fases da análise são dispostas da seguinte forma: Pré-análise: organização do material obtido e verificação da disponibilidade dos mesmos; exploração do material: codificação, categorização e enumeração do material obtido; tratamento dos resultados: interpretação dos resultados conquistados.

Após realizada a leitura e interpretação das falas, estas foram organizadas em dois temas e seis categorias (CARLOMAGNO MC e DA ROCHA LC, 2016). Para o tema "Preparação" foram construídas as categorias: falta de preparo, emoção e humanização. Para o tema "Sentimentos" foram organizadas as categorias: julgamento, empatia e ética.

O projeto de pesquisa deste estudo foi submetido ao Comitê de Ética em Pesquisa envolvendo seres humanos do Centro Universitário Newton Paiva, CAAE 51201221.4.0000.5097. Na primeira página do questionário enviado aos profissionais de enfermagem convidados a participar do estudo, foram prestados esclarecimentos quanto à natureza e objetivos da pesquisa, a qual foi realizada em conformidade com a Resolução 466/12 (BRASIL, 2012b). A coleta de dados foi iniciada após os profissionais aceitarem participar do estudo, mediante aceite do termo de consentimento livre e esclarecido.

\section{RESULTADOS E DISCUSSÃO}

Participaram da pesquisa 19 profissionais. Quanto à caracterização da amostra, todos os respondentes eram mulheres, com predomínio de idade entre 25 a 34 anos (42,1\%). Quanto à formação acadêmica, observou-se maior número de participantes que realizaram alguma especialização p rofissional $(47,4 \%)$. Para o tempo de experiência profissional, houve igualdade de $21,1 \%$ nas seguintes estratificações: menos de 1 ano, de 1 a 5 anos e mais de 20 anos. 


\section{Preparação}

O tema 'Preparação' dispôs acerca de situações que interferem na assistência à mulher em processo de abortamento provocado. Este tema agrega as categorias a seguir: falta de preparo, emoção e humanização.

O preparo técnico e emocional das profissionais é um fator que está diretamente associado a segurança assistencial, como apresentado a seguir:

"Tecnicamente me considero apta. As questões emocionais são mais instáveis e sofrem mais interferência de fatores que não podemos controlar. A assistência contínua gera exaustão emocional" (Entrevistada 1).

"...é papel do enfermeiro cuidar deste paciente, sem julgar o seu ato. A maturidade da profissão, me fez ter um olhar diferente em relação à questão do abortamento provocado. O nosso papel é amenizar os danos físicos e morais deste paciente, que necessita de toda nossa atenção" (Entrevistada 2).

Levando-se em consideração a atuação da enfermagem na promoção, proteção e recuperação da saúde e fundamentando-se nos princípios éticos e legais do ofício profissional, a assistência deve ser pautada no respeito, na ética e nos direitos da pessoa, sem discriminação. Assim, durante à assistência às mulheres em circunstância de aborto, devem ser assegurados privacidade, resolutividade, atendimento integral, acolhimento e atendimento humanizado. Os profissionais de saúde inseridos nesse processo devem estar preparados e sensibilizados para atender essa mulher seguindo esses preceitos (CARDOSO VB, et al., 2021).

As demais entrevistadas demonstraram estar pouco preparadas ou consideraram falta de preparação técnica e emocional para lidar e prestar assistência à mulher em processo de abortamento provocado, como observado nas falas a seguir:

"Gostaria de ter mais preparo técnico, gosto de atender e fazer um acolhimento humanizado" (Entrevistada 3).

"Não tive uma palestra para saber uma forma mais adequada para acolher neste caso" (Entrevistada 4).

"Nesse momento da carreira lido bem. Mas ainda fico mal depois" (Entrevistada 5).

O atendimento ao abortamento, pela equipe de saúde, livre de crenças e rotulações é um processo laborioso visto que as instituições de formação em saúde nem sempre têm engajado no processo de ruptura entre os valores pessoais e a experiência profissional, não preparam os alunos para que controlem seus sentimentos ou para que lidem com informações que transpassam a prática biomédica (BRASIL, 2011).

É importante considerar a idealização desses profissionais quanto à visão de assistência durante o atendimento à mulher em processo de abortamento provocado.

"Abordagem humanizada. Excesso de pensamentos negativos ou julgamentos, precisam estar bem guardados para quando oferecermos o cuidado a uma mulher cujo provocou aborto, não se ache julgada ou excluída. Cada um tem sua escolha e por mais que muitas vezes não conseguimos entender a opinião do outro, como profissional, cabe a nós apenas dar assistência necessária que o cliente precisa naquele momento" (Entrevistada 6).

"O profissional precisa entender que ali ele faz o papel de cuidado aquela mulher de forma holística, se tornando um apoio e criando um espaço aberto para dialogar sobre $o$ assunto. Principalmente para evitar que ela precise passar por essa situação novamente, afinal a mulher sofre um abalo psicológico e principalmente físico com risco de vida" (Entrevistada 7).

"Deve ser uma abordagem humanizada e respeitosa, sem interferência de crenças pessoais, religiosas (...)" (Entrevistada 3). 
É de grande relevância o papel da equipe de enfermagem na promoção de uma assistência segura para que aquela mulher não se torne parte das estatísticas de mortalidade materna, contribuindo também na recuperação física e mental após as consequências causadas durante o processo de abortamento provocado. Há muito o que mudar e evoluir ainda na preparação técnica e emocional da equipe de enfermagem frente ao abortamento provocado (PEREIRA AJ, 2018).

De acordo com o Código de Ética de Enfermagem (CEPE) retratado em seu Art. 15, o profissional de enfermagem deve prestar assistência de enfermagem sem discriminação de qualquer natureza (COFEN, 2017).

\section{Sentimentos}

Os resultados do estudo permitem inferir que o sentimento de insegurança que envolve a assistência prestada à mulher em processo de abortamento provocado torna-se um problema. Ressalta-se nesse tema, também, o quanto os profissionais estão preparados para abordar essa mulher da forma mais humanizada possível. Este tema "Sentimentos" reúne as categorias a seguir: julgamento, empatia e ética.

"Não somos preparados para encarar uma situação dessa, desde a graduação falta esse entendimento. No meu local de trabalho seguimos protocolos rigorosos e acredito que quem já teve oportunidade de cuidar de alguma mulher que teve abortamento provocado, deixa a opinião de lado e a trate como qualquer outra que necessite de assistência" (Entrevistada 8).

"Ainda observo muitos comentários em local inapropriado, julgamentos.... Penso que a equipe precisa de suporte emocional contínuo para trabalhar com os casos. Os profissionais não são preparados para essa lida contínua de "interrupção" da vida como se nada estivesse acontecendo" (Entrevistada 1).

Os sentimentos dos profissionais ao prestarem assistência de enfermag em a uma paciente que provocou o aborto são relatados como empatia, tristeza, sensibilização, desconforto e insegurança. Quanto ao preparo técnico desses profissionais, de acordo com a opinião dos entrevistados, a maioria considera que em seu local de trabalho os profissionais de enfermagem não sabem lidar com as situações do abortamento provocado.

Em países onde o aborto não é permitido, muitas mulheres podem sofrer desprezo, práticas discriminatórias, negligência, ausência de consentimento, ausência de privacidade e violência verbal nos serviços de saúde, o que gera desgosto e que interfere de forma negativa na prestação da assistência, gerando um obstáculo, que tem repercussão integral na saúde da mulher (MADEIRO AP e RUFINO AC, 2017). Embora haja uma política pública focada no atendimento humanizado ao aborto, alguns profissionais da pesquisa ainda não sabem lidar com as situações de abortamento provocado (BRASIL, 2011).

Identificou-se também, o limite onde os profissionais conseguem prestar uma assistência de acordo com o Código de Ética profissional sem deixar suas questões pessoais interferirem no atendimento.

"Sem julgamentos. Nosso papel é fundamental no processo para amenizar a culpa deste paciente, frente ao abortamento provocado" (Entrevistada 9).

"Com respeito! Acho importante que haja apoio psicológico com profissional capacitado para abordar a mulher sem preconceito e para ajudá-la a vivenciar o processo e os motivos que levaram a decisão de abortar" (Entrevistada 10).

"Com rigor técnico e ético. Mantendo-se sempre que possível a empatia com a mulher" (Entrevistada 11).

Observa-se na pesquisa que a maior parte dos profissionais estão de acordo com os preceitos éticos do Código de Ética dos Profissionais de Enfermagem, o qual destaca que a assistência de enfermagem necessita ser exercida com competência, responsabilidade e dignidade, sem nenhuma forma de violência e satisfazendo as necessidades de saúde e preservando a autonomia das pessoas (COFEN, 2017). Além disso, 
a Constituição Federal Brasileira reconhece, há mais de 30 anos, que a assistência à saúde deve ser universal e integral em todos os níveis de atenção livre de privilégios e preconceitos (BRASIL, 1988).

Nesse sentido, a assistência humanizada nos casos de aborto, deve percorrer os princípios fundamentais da bioética: a autonomia, a beneficência, a não-maleficência e a justiça. Todo e qualquer profissional da saúde tem o dever de acatar pela garantia desses direitos, independentemente do contexto (PITILIN EB, et al., 2016).

\section{CONSIDERAÇÕES FINAIS}

O estudo mostrou que há falta de consenso em relação aos sentimentos dos profissionais diante da situação. Observa-se também que alguns profissionais ainda presenciam comentários preconceituosos e antiéticos vindo de colegas de trabalho que não conseguem deixar suas questões pessoais de lado e realizar um atendimento humanizado. Consideramos a partir do estudo que, mesmo avançando nas discussões relativas à temática, ainda há poucas pesquisas sobre o ponto de vista profissional em relação ao aborto provocado, além de falha de informações desde a graduação e capacitações específicas para esse tipo de assistência, a qual vai muito além do tecnicismo. É essencial ampliar ainda mais as discussões e reflexões sobre esse tema, com o intuito de humanizar a assistência de enfermagem às mulheres que passam pelo processo de abortamento provocado, tornando assim o menos traumático possível para ela.

\section{REFERÊNCIAS}

1. BARDIN L. Análise de Conteúdo. 4aㅡ ed. Lisboa: Edições 70, 2010;118p.

2. BRASIL. Decreto-Lei no 2848, de 7 de dezembro de 1940. 1940. Disponível em: http://www.planalto.gov.br/ccivil_03/decreto-lei/del2848.html. Acessado em:18 nov. 2021.

3. BRASIL. Constituição da República Federativa do Brasil de 1988.1988. Disponível em: http://www.planalto.gov.br/ccivil_03/constituicao/constituicao.html. Acessado em:18 nov. 2021.

4. BRASIL. Política Nacional de Atenção Integral à Saúde da Mulher. Princípios e Diretrizes. 2004. Disponível em: https://bvsms.saude.gov.br/bvs/publicacoes/politica_nac_atencao_mulher.pdf. Acessado em:22 set. 2021.

5. BRASIL. Atenção Humanizada ao Abortamēnto. Norma Técnica. 2011. Disponível em: https://bvsms.saude.gov.br/bvs/publicacoes/atencao_humanizada_abortamento_norma_tecnica_2ed.pdf. Acessado em:18 nov. 2021.

6. BRASIL. Arguição de descumprimento de preceito fundamental 54 Distrito Federal de 12 de abril de 2012. 2012a. Disponível em: https://www.conjur.com .br/dl/acordao-interrupcao-gravidez-anencefalo.pdf. Acesso em: 18 nov. 2021.

7. BRASIL. Resolução no 466, de 12 de dezembro de 2012 . 2012b. Disponível em: http://www.conselho.saude.gov.br/resolucoes/2012/Reso466.pdf. Acessado em:18 nov. 2021.

8. CARDOSO VB, et al. Humanização na assistência de enfermagem à mulher em situação pós-abortamento. Revista de Enfermagem UFPE Online, 2021;15(1): e245659.

9. CARLOMAGNO MC, DA ROCHA LC. Como criar e classificar categorias para fazer análise de conteúdo: uma questão metodológica. Revista Eletrônica de Ciência Política, 2016; 7(1): 173-187.

10. CONSELHO FEDERAL DE ENFERMAGEM (COFEN). Resolução no 564/2017. Aprova o novo Código de Ética dos Profissionais de Enfermagem. 2017. Disponível em: http://www.cofen.gov.br/resolucao-cofen-no5642017_59145.html. Acessado em: 18 nov. 2021.

11. CONSELHO FEDERAL DE ENFERMAGEM (COFEN). Uma mulher morre a cada 2 dias por aborto inseguro, diz Ministério da Saúde. 2018. Disponível em: http://www.cofen.gov.br/uma-mulher-morre-a-cada-2-dias-por-causa-doaborto-inseguro-diz-ministerio-da-saude_64714.html. Acessado em:18 nov. 2021.

12. DINIZ D, et al. Pesquisa Nacional de Aborto 2016. Ciência \& Saúde Coletiva, 2017;22 (2): 653-660.

13. HECKATHORN DD. Respondent-Driven Sampling: A New Approach to the Study of Hidden Populations. Social problems, 1997;44(2):174-199.

14. MADEIRO AP, RUFINO AC. Maus-tratos e discriminação na assistência ao aborto provocado: a percepção das mulheres em Teresina, Piauí, Brasil. Ciência \& Saúde Coletiva, 2017;22(8):2771-2780.

15. MENDES RM, MISKULIN RGS. A análise de conteúdo como uma metodologia. Cadernos de Pesquisa, 2017; 47(165): 1044-1066.

16. PEREIRA AJ. O Papel do Profissional Enfermeiro Frente ao Aborto em seus Aspectos Jurídicos, Físico e Emocionais. Revista Científica Multidisciplinar Núcleo do Conhecimento, 2018;7:95-115.

17. PITILIN EB, et al. Assistência de enfermagem em situações de aborto induzido/provocado: uma revisão integrativa da literatura. Enfermería Global, 2016;15(43):453-466.

18. SANTOS VC, et al. Criminalização do aborto no Brasil e implicações à saúde pública. Revista Bioética, 2013; 21(3): 494-508.

19. SILVEIRA P, et al. Experiências de abortos provocados em clínicas privadas no Nordeste brasileiro. Cadernos de Saúde Pública, 2016;32(2): e00004815.

20. SOARES FP, etal. Atenção humanizada à mulher em processo de abortamento no mesmo ambiente das parturientes. Revista Atualiza Saúde, 2018;7(7): 95-99. 